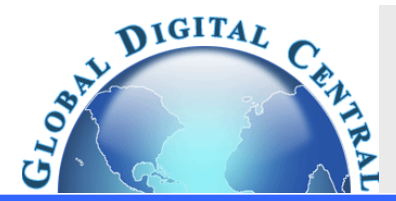

Frontiers in Heat and Mass Transfer

Available at www.ThermalFluidsCentral.org

\title{
MHD SLIP FLOW AND HEAT TRANSFER OVER AN EXPONENTIALLY STRETCHING PERMEABLE SHEET EMBEDDED IN A POROUS MEDIUM WITH HEAT SOURCE
}

\author{
P. R. Sharma ${ }^{a}$, Sushila Choudhary ${ }^{a},{ }^{*}$, O. D. Makinde ${ }^{b}$ \\ ${ }^{a}$ Department of Mathematics, University of Rajasthan, Jaipur-302004, India \\ ${ }^{b}$ Faculty of Military Science, Stellenbosch University, South Africa
}

\begin{abstract}
Steady two dimensional laminar magnetohydrodynamic (MHD) slip flow and heat transfer of a viscous incompressible and electrically conducting fluid past over a flat exponentially non-conducting stretching porous sheet embedded in a porous medium with non uniform permeability in the presence of non uniform heat source is investigated. The governing equations of velocity and temperature distributions are solved numerically and the effects of different physical parameters are shown through graphs. The rate of shear stress and the rate of heat transfer at the sheet are derived, discussed numerically and their numerical values for various values of physical parameters are presented through tables.
\end{abstract}

Keywords: Steady, MHD, stretching sheet, porous medium, heat source, velocity slip, thermal slip, skin friction coefficient and Nusselt number.

\section{INTRODUCTION}

The study of hydromagnetic electrically conducting fluid flow involving heat transfer over stretching porous sheet is of great importance in many processes as modern metallurgical and metalworking processes. This field has attracted the attention of many researchers because of its possible applications in soil sciences, astrophysics, geophysics, nuclear power reactors etc. In cooling process of nuclear fission reactors, liquid sodium is pumped around using electromagnetic forces. In medical science, an advanced method is used for precisely delivery of medicine to cancer affected organs, in which MHD equations and finite element analysis are used to study the interaction between the magnetic fluid particles in the bloodstream and the external magnetic field. The study of fluid flow through porous medium has become predictable in the extraction of crude oil from the pores of rocks and filtration of solids from liquids. Fluid flow through porous medium also has applications in environment such as flow of ground water through soil and rocks, which is important for agriculture and pollution control. The suction/injection process has its importance in many engineering activities such as in the thermal oil recovery, designing of thrust bearing and radial diffusers. Suction is also applied to chemical processes to remove reactants. In heat pumping technology natural heat sources/sinks like air, ground, water etc. are used. This technology is used in compressors, refrigerators and air conditioners.

Heat transfer of a continuous stretching surface with suction or blowing was analyzed by Chen and Char (1988). Kumaran and Ramanaiah (1996) discussed the flow over a stretching sheet. Heat and mass transfer in the boundary layers on an exponentially stretching continuous surface has been studied by Magyari and Keller (1999). Elbashbeshy (2001) considered heat transfer over an exponentially stretching continuous surface with suction. Slip flow past a stretching surface was investigated by Andersson (2002). Miklavcic and Wang (2006) analyzed viscous flow due to a shrinking sheet. Hydromagnetic flow and heat transfer adjacent to a stretching vertical sheet with prescribed surface heat flux was studied by Aman and Ishak (2010). Pal and Hiremath (2010) considered computational modeling of heat transfer over an unsteady stretching surface embedded in a porous medium. Boundary layer flow and heat transfer over a stretching sheet with Newtonian heating was studied by Salleh et al. (2010). Sharma and Singh (2010) investigated steady MHD natural convection flow with variable electrical conductivity and heat generation along an isothermal vertical plate.

MHD boundary layer flow due to an exponentially stretching sheet with radiation effect was presented by Ishak (2011). Yao et al. (2011) studied heat transfer on a generalized stretching/shrinking wall with convective boundary condition. Heat transfer in a fluid through a porous medium over a permeable stretching surface with thermal radiation and variable thermal conductivity was analyzed by Cortell (2012). Hayat (2012) considered three-dimensional flow of a Jeffery fluid over a linearly stretching sheet. Hydromagnetic boundary layer flow over stretching surface with thermal radiation has been discussed by Soid et al. (2012). Mandal and Mukhopadhyay (2013) presented heat transfer analysis for fluid flow over an exponentially stretching porous sheet with surface heat flux in porous medium. Slip effects on MHD boundary layer flow over an exponentially stretching sheet with suction/blowing and thermal radiation shown by Mukhopadhyay (2013). Norhafizah et al. (2013) studied numerical solution of flow and heat transfer over a stretching sheet with Newtonian heating using the Keller Box Method. Singh and Makinde (2015) presented a similarity solution for the combined effects of velocity slip and temperature jump on boundary layer flow over a moving surface. The MHD slip flow of a conducting Casson nanofluid over a convectively heated stretching sheet was numerically studied by Ibrahim and Makinde (2016a). Other relevant papers with respect to MHD flow over a stretching sheet include Ibrahim and Makinde (2016b); Khan et al. (2016).

The aim of the paper is to investigate steady two dimensional laminar MHD flow of a viscous incompressible and electrically conducting fluid past over a flat exponentially non-conducting 
stretching porous sheet in the presence of non uniform heat source. The governing equations of motion and energy are solved numerically using Runge-Kutta fourth order method along with shooting technique. The effects of the Hartmann number, permeability parameter, Prandtl number, heat source parameter, velocity slip parameter, thermal slip parameter and suction parameter on velocity and temperature distributions are investigated and shown through graphs. The rate of shear stress as skin friction coefficient and the rate of heat transfer as the Nusselt number are derived, discussed numerically and their numerical values for various values of physical parameters are presented through Table 1 and Table 2.

\section{MATHEMATICAL FORMULATION OF THE PROBLEM}

Steady two dimensional laminar flow of a viscous incompressible and electrically conducting fluid past over a flat exponentially nonconducting stretching porous sheet embedded in a porous medium with non uniform permeability is considered. The $x$-axis is taken in the direction along the stretching sheet and $y$-axis is taken normal to it.

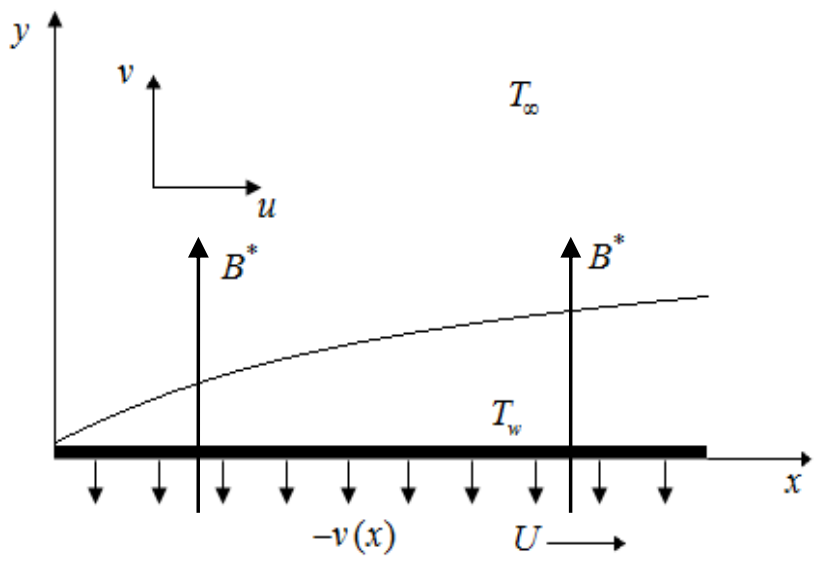

Fig. 1 Physical model and the coordinate system.

The fluid flow confined to $y>0$. The flow is generated by the action of two equal and opposite forces along the $x$-axis so that the wall is stretched keeping the origin fixed. The surface is assumed to be highly elastic and is stretched in the $x$-direction with the velocity $U=U_{0} e^{\frac{x}{l}}$. A non uniform magnetic field $B^{*}=B_{0} e^{\frac{x}{2 l}}$ is applied along the $y$-direction. The magnetic Reynolds is taken to be small and therefore the induced magnetic field is neglected. It is assumed that the temperature of the sheet $T_{w}$ is variable and given by $T_{w}=T_{\infty}+T_{0} e^{\frac{x}{2 l}}$. A non uniform heat source is also applied. All the fluid properties are assumed to be constant throughout the motion. Under these assumptions, the governing boundary layer equations [Bansal (1977), Bansal (1994), Schlichting and Gersten (2003)] are

$\frac{\partial u}{\partial x}+\frac{\partial v}{\partial y}=0$

$u \frac{\partial u}{\partial x}+v \frac{\partial u}{\partial y}=v \frac{\partial^{2} u}{\partial y^{2}}-\left(\frac{\sigma_{e} B^{* 2}}{\rho}+\frac{v}{K^{*}}\right) u$,

$u \frac{\partial T}{\partial x}+v \frac{\partial T}{\partial y}=\frac{\kappa}{\rho C_{p}} \frac{\partial^{2} T}{\partial y^{2}}+\frac{Q^{*}}{\rho C_{p}}\left(T-T_{\infty}\right)$,

where $K^{*}=K_{0} e^{-\frac{x}{l}}$ is the non uniform permeability of the medium and $Q^{*}=Q_{0} e^{\frac{x}{l}}$ is the non uniform heat source.
The boundary conditions are

$y=0: u=U+L^{*} \frac{\partial u}{\partial y}, v=-v(x), T=T_{w}+D^{*} \frac{\partial T}{\partial y} ;$

$y \rightarrow \infty: u \rightarrow 0, T \rightarrow T_{\infty}$,

where $v(x)\left(=V_{0} e^{\frac{x}{2 l}}\right)$ is the suction velocity at the sheet, $L^{*}\left(=L_{0} e^{-\frac{x}{2 l}}\right)$ is the velocity slip factor and $D^{*}\left(=D_{0} e^{-\frac{x}{2 l}}\right)$ is the thermal slip factor.

\section{METHOD OF SOLUTION}

Introducing the following similarity transformations

$\eta=y \sqrt{\frac{U_{0}}{2 v l}} e^{\frac{x}{2 l}}, \theta(\eta)=\frac{T-T_{\infty}}{T_{w}-T_{\infty}}, \psi=\sqrt{2 v U_{0} l} e^{\frac{x}{2 l}} f(\eta)$,

The stream function $\psi$ is defined as

$u=\frac{\partial \psi}{\partial y}$ and $v=-\frac{\partial \psi}{\partial x}$,

which identically satisfies the continuity Eq. (1). Using Eq. (5) into the Eq. (6), we have the velocity components as given below

$$
\begin{aligned}
& u=U_{0} e^{\frac{x}{l}} f^{\prime}(\eta), \\
& v=-\sqrt{\frac{v U_{0}}{2 l}} e^{\frac{x}{2 l}}\left(\eta f^{\prime}(\eta)+f(\eta)\right),
\end{aligned}
$$

where prime denotes the differentiation with respect to $\eta$. Now using Eqs. (5) and (7) into the Eqs. (2) and (3), we have

$$
\begin{aligned}
& f^{\prime \prime \prime}+f f^{\prime \prime}-2 f^{\prime 2}-\left(M+\frac{1}{K}\right) f^{\prime}=0, \\
& \theta^{\prime \prime}+\operatorname{Pr}\left(f \theta^{\prime}-\theta f^{\prime}\right)+2 \operatorname{Pr} Q \theta=0,
\end{aligned}
$$

where $M\left(=\frac{2 \sigma B_{0}^{2} l}{\rho U_{0}}\right)$ is the Hartmann number, $K\left(=\frac{U_{0} K_{0}}{2 v l}\right)$ is the permeability parameter, $\operatorname{Pr}\left(=\frac{\mu C_{p}}{\kappa}\right)$ is the Prandtl number and $Q\left(=\frac{2 Q_{0} l}{\rho C_{p} U_{0}}\right)$ is the heat source parameter.

The boundary conditions in dimensionless form are reduced to $\eta=0: f=S, f^{\prime}=1+S_{v} f^{\prime \prime}, \theta=1+S_{T} \theta^{\prime} ;$ $\eta \rightarrow \infty: f^{\prime} \rightarrow 0, \theta \rightarrow 0$,

where $S\left(=V_{0} \sqrt{\frac{2 l}{v U_{0}}}\right)$ is the suction parameter, $S_{v}\left(=L_{0} \sqrt{\frac{U_{0}}{2 v l}}\right)$ is the velocity slip parameter and $S_{T}\left(=D_{0} \sqrt{\frac{U_{0}}{2 v l}}\right)$ is the thermal slip parameter. 


\subsection{Coefficient of Skin friction and Nusselt number}

Rate of shear stress in terms of coefficient of skin friction at the sheet is given by

$C_{f}=\frac{2 \tau_{w}}{\rho U_{0}^{2}}=\left(\frac{R e_{x}}{2} e^{\frac{x}{l}}\right)^{-\frac{1}{2}} f^{\prime \prime}(0)$,

where $\tau_{w}$ is the wall shear stress given by $\tau_{w}=\mu\left(\frac{\partial u}{\partial y}\right)_{y=0}$.

Rate of heat transfer in terms of Nusselt number at the sheet is given by

$N u=\frac{l q_{w}}{\kappa\left(T_{w}-T_{\infty}\right)}=-\left(\frac{R e_{x}}{2} e^{\frac{x}{l}}\right)^{\frac{1}{2}} \theta^{\prime}(0)$,

where $q_{w}$ is the rate of heat transfer given by $q_{w}=-\kappa\left(\frac{\partial T}{\partial y}\right)_{y=0}$.

\section{NUMERICAL SOLUTION}

The coupled nonlinear ordinary second order differential Eqs. (8) and (9) along with boundary conditions (10) are solved numerically using MATLAB software. First we convert the boundary value problem into a system of initial value problems as follows:

$f^{\prime}=f_{1} ; \quad f_{1}{ }^{\prime}=f_{2} ; \quad f_{2}{ }^{\prime}=-f f_{2}+2 f_{1}{ }^{2}+\left(M+\frac{1}{K}\right) f_{1}$,

and

$\theta^{\prime}=f_{3} ; \quad f_{3}^{\prime}=-\operatorname{Pr}\left(f f_{3}-\theta f_{1}\right)-2 \operatorname{Pr} Q \theta$.

The boundary conditions are

$f(0)=S, f_{1}(0)=1+S_{v} f_{2}(0), \theta(0)=1+S_{T} f_{3}(0)$.

To solve Eqs. (13) and (14) with boundary conditions (15) as a system of initial value problems we must need the values for $f_{2}(0)$ i.e. $f^{\prime \prime}(0)$ and $f_{3}(0)$ i.e. $\theta^{\prime}(0)$ but no such values are given. Therefore initial guess values for $f^{\prime \prime}(0)$ and $\theta^{\prime}(0)$ are chosen arbitrarily and then we solve the system of initial value problems by using Runge-Kutta fourth order method along with shooting technique. We compare the calculated values of $f^{\prime}(\eta)$ and $\theta(\eta)$ with the given boundary conditions at $\eta \rightarrow \infty$ i.e. $\eta_{\infty}$. We adjust the values of $f^{\prime \prime}(0)$ and $\theta^{\prime}(0)$ to get better approximation of $f^{\prime}(\eta)$ and $\theta(\eta)$ at $\eta_{\infty}$. In this method, it is necessary to choose a suitable finite value of $\eta_{\infty}$. Here a suitable finite value $\eta_{\infty}=2$ is chosen, which depends on the values of the parameters used. In addition the relative error tolerance to $10^{-6}$ is considered for better convergence.

\section{RESULTS AND DISCUSSION}

Effects of different physical parameters on velocity and temperature distributions are shown through figures when $M=0.5, K=1, P r=0.71, Q=0.5, S=3, S_{v}=0.1$ and $S_{T}=0.1$.

Figure 2 shows the effect of permeability parameter on the velocity of the fluid. It is observed that velocity increases with the increment of the permeability parameter. Increment in permeability parameter denotes the increment in the porosity feature of the medium. Clearly, as the porosity of medium is increased, velocity of the fluid through that medium is also increased because fluid got more space with fewer disturbances to flow through medium.

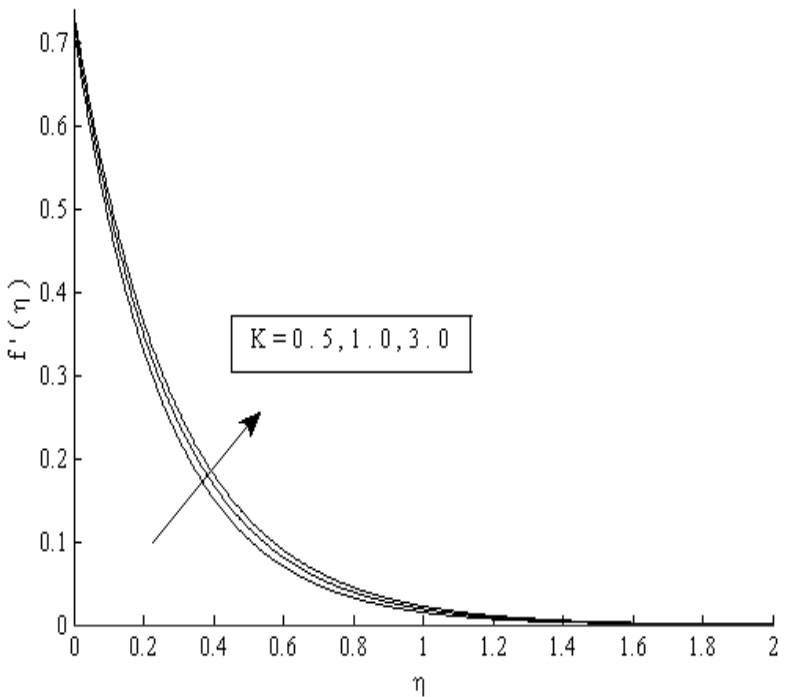

Fig. 2 Velocity distribution for different values of $K$.

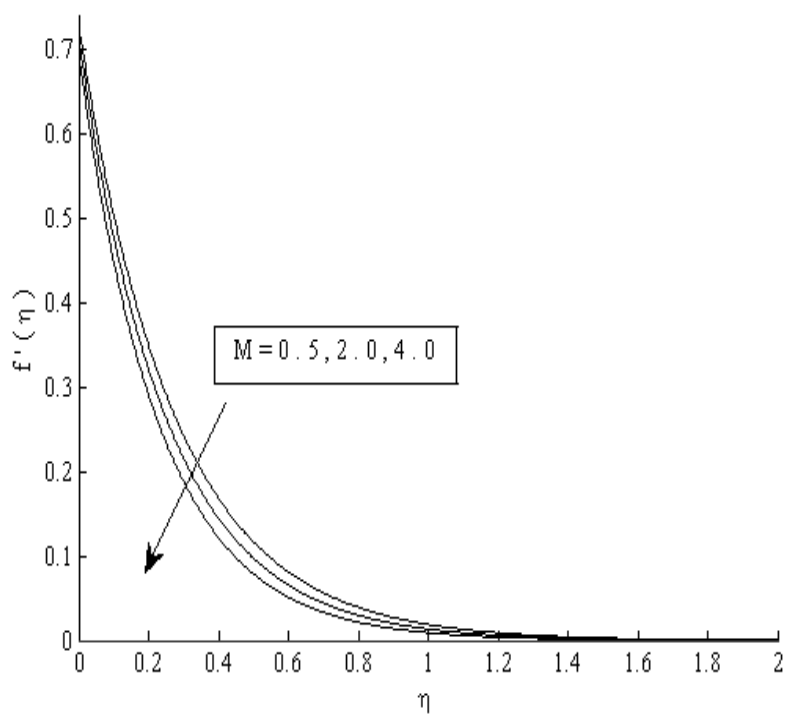

Fig. 3 Velocity distribution for different values of $M$.

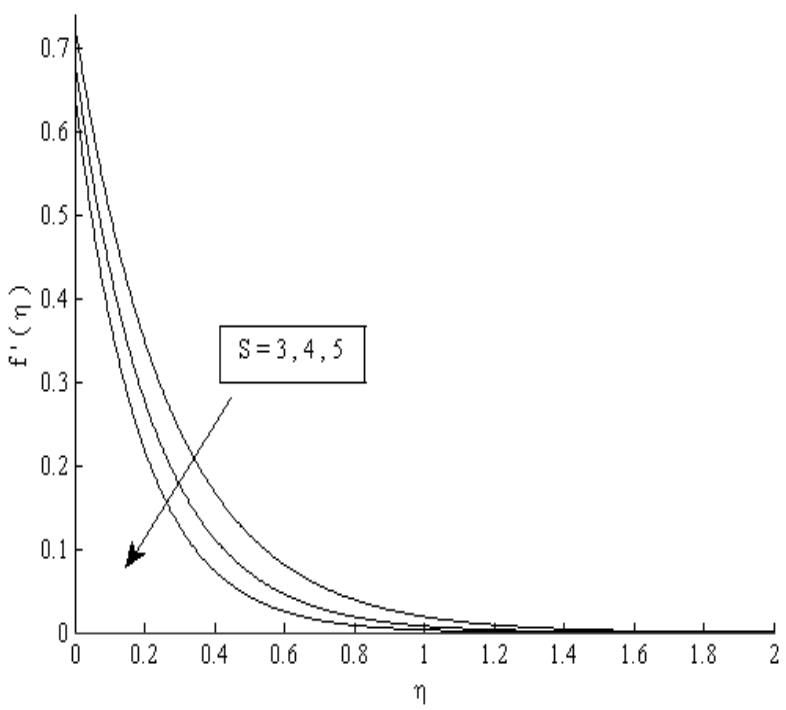

Fig. 4 Velocity distribution for different values of $S$. 
The effect of magnetic parameter (Hartmann number) on velocity of the fluid is displayed in Fig. 3. Due to magnetic field, a resisting force is generated in the flow which is called Lorentz force. This force caused a decline in velocity of the fluid. Therefore as the Hartmann number increases, fluid velocity decreases. It is seen from Fig. 4 that velocity decreases with the increment of suction parameter. Suction parameter shows the porosity of the sheet. As the size of pores of the sheet is increased the flow through the sheet is increased which resist the flow along the sheet. That is the reason of the reduction of fluid flow along the sheet in magnitude.

The effect of velocity slip parameter on fluid velocity is presented in Fig. 5. It is observed that velocity decreases with the increment in the velocity slip parameter. Increment in Hartmann number implies the increment in the strength of Lorentz force. Due to this resisting force, temperature of the fluid is increased. This effect can be observed from Fig. 6. Temperature profile is shown for different values of heat source parameter in Fig. 7. Increment in heat source parameter indicates that external heat is provided to fluid and clearly it causes the enhancement of the fluid temperature. The effect of velocity slip parameter is presented through Fig. 8 and it is observed that fluid temperature increases with the increase of the velocity slip parameter.

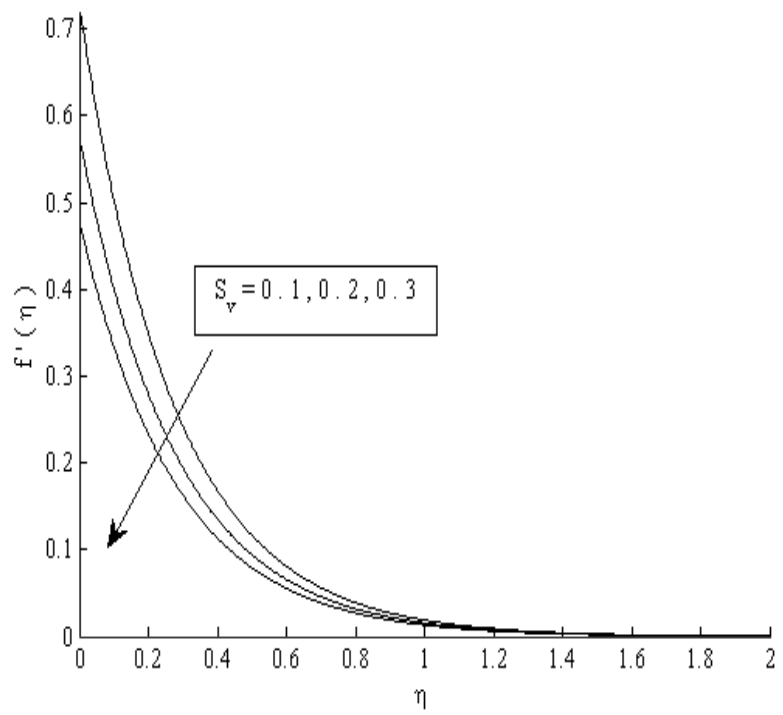

Fig. 5 Velocity distribution for different values of $S_{v}$.

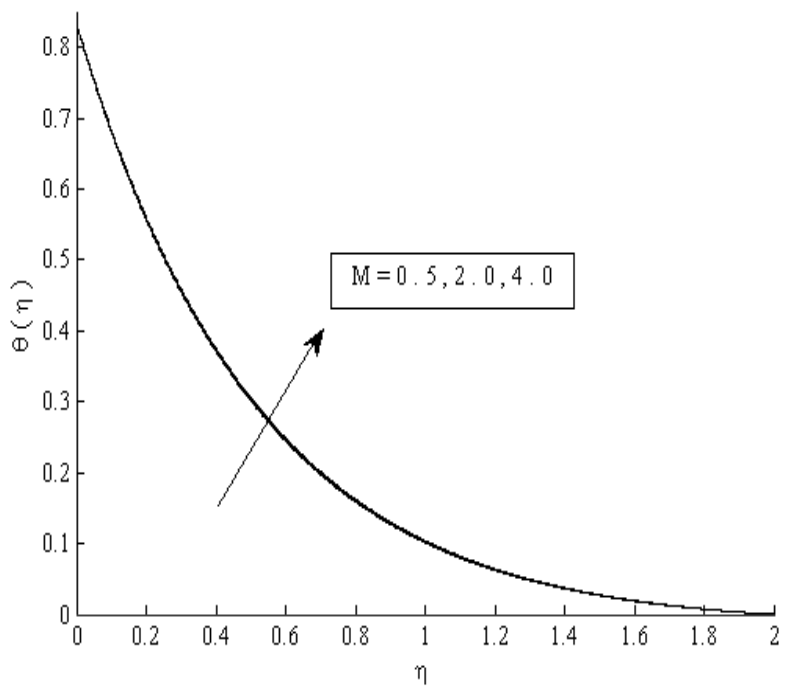

Fig. 6 Temperature distribution for different values of $M$.

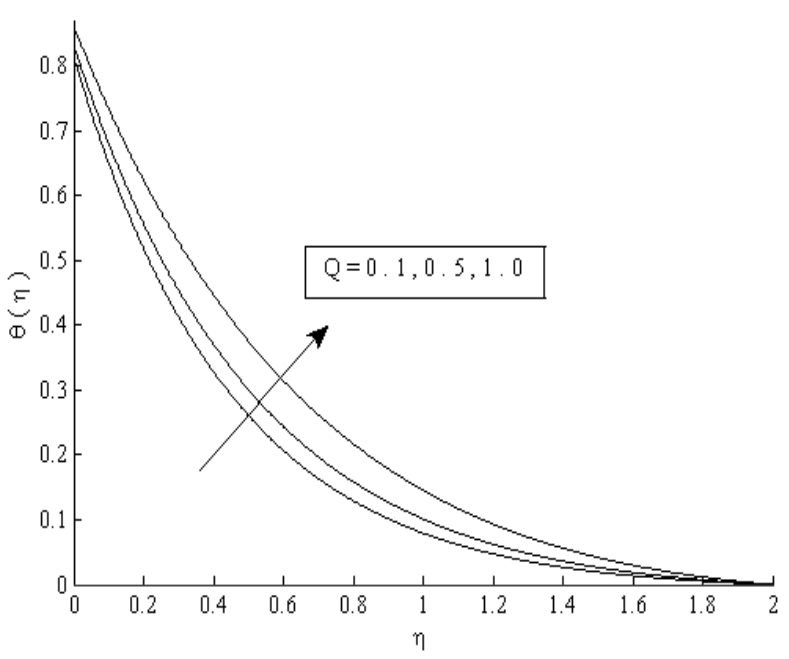

Fig. 7 Temperature distribution for different values of $Q$.

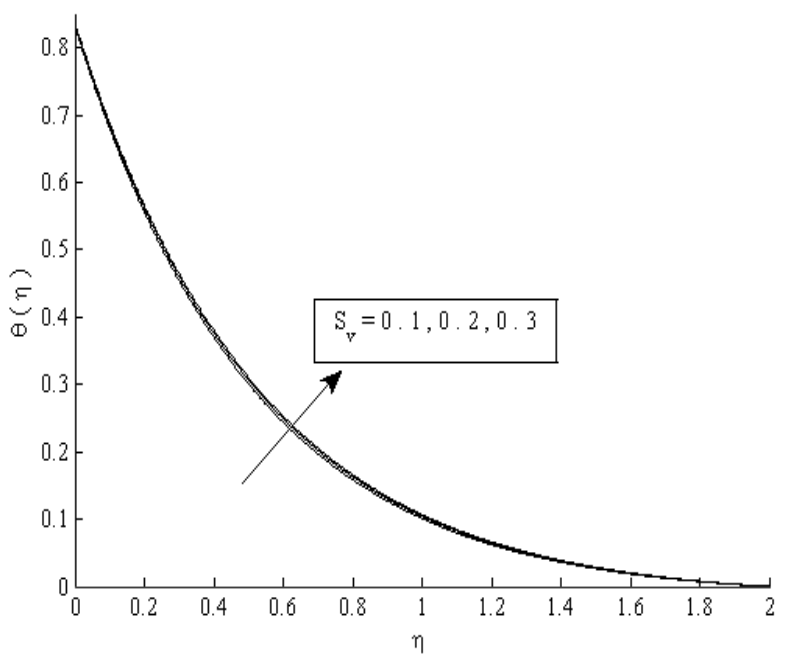

Fig. 8 Temperature distribution for different values of $S_{v}$.

Prandtl number is the ratio of momentum diffusivity to thermal diffusivity. Figure 9 shows the effect of Prandtl number on fluid velocity. As the Prandtl number increases thermal conductivity of the fluid decreases, therefore fluid temperature decreases.

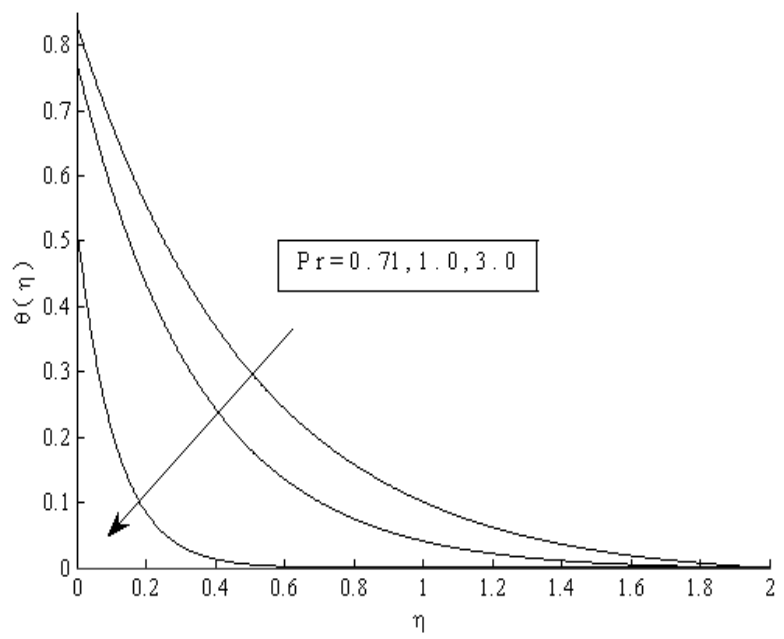

Fig. 9 Temperature distribution for different values of $P r$. 
Figure 10 shows the effect of suction parameter on fluid temperature and it is observed that fluid temperature decreases with the increase of suction parameter. The effect of thermal slip parameter on fluid temperature is presented in Fig. 11 and it is noted that fluid temperature decreases with the increase of thermal slip parameter.

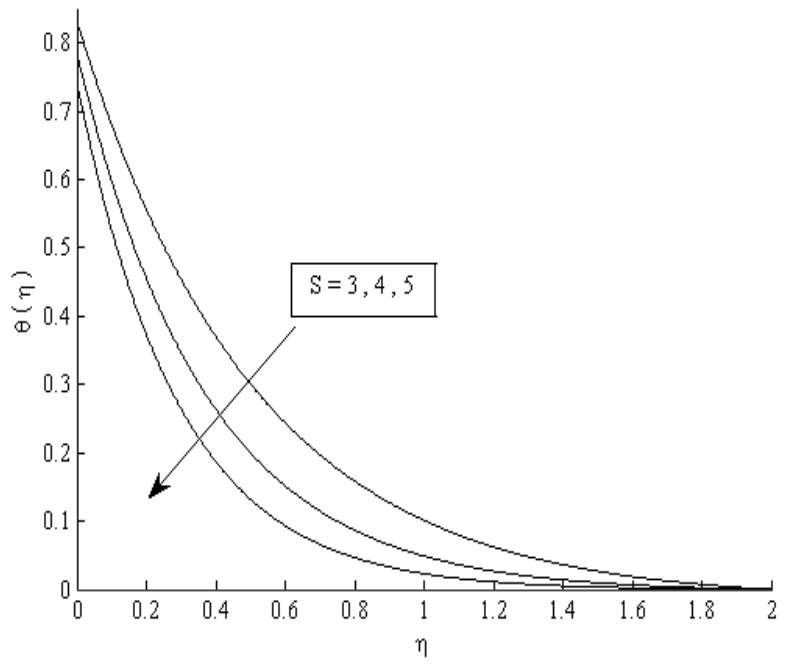

Fig. 10 Temperature distribution for different values of $S$.

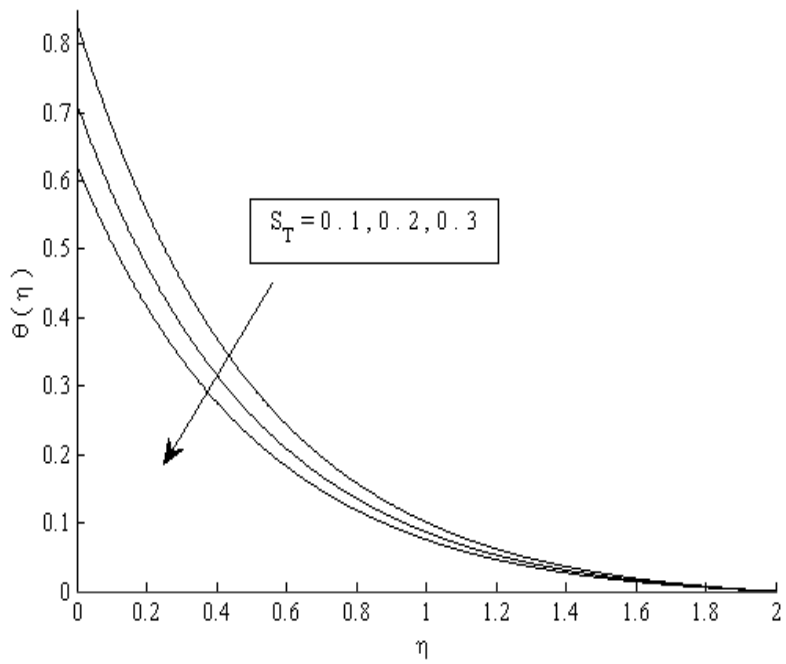

Fig. 11 Temperature distribution for different values of $S_{T}$.

Table 1 Numerical values of $f^{\prime \prime}(0)$ for different values of physical parameters.

\begin{tabular}{|l|l|l|l|l|}
\hline$K$ & $M$ & $S$ & $S_{v}$ & $f^{\prime \prime}(0)$ \\
\hline 1 & 0.5 & 3 & 0.1 & -2.7051005 \\
\hline 3 & 0.5 & 3 & 0.1 & -2.6221080 \\
\hline 1 & 2 & 3 & 0.1 & -2.8681380 \\
\hline 1 & 0.5 & 4 & 0.1 & -3.1313106 \\
\hline 1 & 0.5 & 4 & 0.3 & -1.7351530 \\
\hline
\end{tabular}

It is observed from Table 1 that the skin friction coefficient increases due to increase in the permeability parameter or velocity slip parameter; while it decreases with the increase of the Hartmann number or suction parameter.

Table 2 Numerical values of $-\theta^{\prime}(0)$ for different values of physical parameters.

\begin{tabular}{|l|l|l|l|l|l|l|l|}
\hline$K$ & $M$ & $P r$ & $Q$ & $S$ & $S_{v}$ & $S_{T}$ & $-\theta^{\prime}(0)$ \\
\hline 1 & 0.5 & 0.71 & 0.5 & 3 & 0.1 & 0.1 & 1.677319 \\
\hline 3 & 0.5 & 0.71 & 0.5 & 3 & 0.1 & 0.1 & 1.682538 \\
\hline 1 & 2 & 0.71 & 0.5 & 3 & 0.1 & 0.1 & 1.667540 \\
\hline 1 & 0.5 & 1.0 & 0.5 & 3 & 0.1 & 0.1 & 2.241582 \\
\hline 1 & 0.5 & 0.71 & 1 & 3 & 0.1 & 0.1 & 1.383828 \\
\hline 1 & 0.5 & 0.71 & 0.5 & 4 & 0.1 & 0.1 & 2.144508 \\
\hline 1 & 0.5 & 0.71 & 0.5 & 3 & 0.3 & 0.1 & 1.632893 \\
\hline 1 & 0.5 & 0.71 & 0.5 & 3 & 0.1 & 0.3 & 1.255982 \\
\hline
\end{tabular}

It is depicted from Table 2 that due to increase of permeable parameter, Prandtl number or suction parameter, the Nusselt number increases; while it decreases with the increase of Hartmann number, heat source parameter, velocity slip parameter or thermal slip parameter.

\section{CONCLUSIONS}

Steady two dimensional laminar boundary layer flow and heat transfer of a viscous incompressible and electrically conducting fluid past over a flat exponentially non-conducting stretching porous sheet in the presence of non uniform transverse magnetic field and non uniform heat source are analyzed numerically. Effect of different physical parameters on fluid velocity, fluid temperature, skin friction coefficient and Nusselt number are investigated and the following observations are made:

- As the Hartmann number increases, the fluid velocity decreases; whereas the fluid temperature increases.

- An increase in heat source parameter results an increase in the fluid temperature

- The fluid velocity and fluid temperature decrease with the suction parameter.

- As the velocity slip parameter increases, the fluid velocity decreases, while opposite behavior is seen for fluid temperature.

- The fluid temperature increases with the increase of heat source parameter; while it decreases with the Prandtl number.

- The skin friction coefficient and the Nusselt number increase due to increase in the permeability parameter.

- Due to increase of Prandtl number, Nusselt number increases; while Nusselt number decreases with the increase of heat source parameter.

\section{NOMENCLATURES}

$B_{0}$

$C_{f}$

$C_{p}$

$D_{0}$

$f$

$K_{0}$

$L_{0}$

$q_{w}$

$Q_{0}$

$R e_{x}$

$\mathrm{Nu}$
Constant magnetic field intensity, $\mathrm{kg} / \mathrm{s}^{2} \mathrm{~A}$

Skin friction coefficient

Specific heat at constant pressure, $\mathrm{J} / \mathrm{kgK}$

Initial value of thermal slip factor, $m$

Dimensionless stream function

Initial permeability of the medium, $m^{2}$

Initial value of velocity slip factor, $m$

Heat flux, $W / m^{2}$

Constant initial heat source, $\mathrm{J} / \mathrm{m}^{3} \mathrm{~s} K$

Local Reynolds number

Nusselt number 
$T$

$T_{0}$

$T_{w}$

$T_{\infty}$

$U$

$U_{0}$

$U_{\infty}$

$V_{0}$

$l$

$u$

$v$

$x, y$

Greek Symbols

$\eta$

$\theta$

$\kappa$

$\mu$

$\rho$

$\sigma_{e}$

$\psi$

Abbreviations

MHD
Fluid temperature within the boundary layer, $K$

Temperature increase along the sheet, $K$

Temperature of the sheet, $K$

Temperature far away from the sheet, $K$

Stretching velocity, $\mathrm{m} / \mathrm{s}$

Reference velocity, $\mathrm{m} / \mathrm{s}$

Free stream velocity, $\mathrm{m} / \mathrm{s}$

Initial strength of suction, $\mathrm{m} / \mathrm{s}$

Reference length, $m$

Dimensionless velocity in $x$ direction, $\mathrm{m} / \mathrm{s}$

Dimensionless velocity in $y$ direction, $\mathrm{m} / \mathrm{s}$

Axial and transverse co-ordinates, $m$

Similarity variable

Dimensionless temperature

Thermal conductivity, $W / m K$

Viscosity, $K g / m s$

Kinematic viscosity, $\mathrm{m}^{2} / \mathrm{s}$

Density, $\mathrm{Kg} / \mathrm{m}^{3}$

Electric conductivity

Stream function

Magnetohydrodynamics

\section{REFERENCES}

Aman, F. and Ishak, A., 2010, "Hydromagnetic Flow and Heat Transfer Adjacent to a Stretching Vertical Sheet with Prescribed Surface Heat Flux," Heat and Mass Transfer, 46, 615-620.

https://dx.doi.org/10.1007/s00231-010-0606-6

Andersson, H.I., 2002, "Slip Flow Past a Stretching Surface," Acta Mech., 158, 121-125.

https://dx.doi.org/10.1007/BF01463174

Bansal, J.L., 1977, Viscous Fluid Dynamics, Oxford \& IBM Pub. Co., New Delhi, India.

Bansal, J.L., 1994, Magnetofluiddynamics of Viscous Fluid, Jaipur Publishing House, Jaipur, India.

Chen, C.K. and Char, M.I., 1988, "Heat Transfer of a Continuous Stretching Surface with Suction or Blowing," J. Math. Anal. Appl., 135(2), 568-580.

http://dx.doi.org/10.1016/0022-247X(88)90172-2

Cortell, R., 2012, "Heat Transfer in a Fluid through a Porous Medium over a Permeable Stretching Surface with Thermal Radiation and Variable Thermal Conductivity," Can. J. Chem. Eng., 90, 1347-1355. https://dx.doi.org/10.1002/cice.20639

Elbashbeshy, E.M.A., 2001, "Heat Transfer over an Exponentially Stretching Continuous Surface with Suction," Arch. Mech., 53(6), 643651.

http://rcin.org.pl

Hayat, T., Awais, M. and Obaidat, S., 2012, "Three-Dimensional Flow of a Jeffery Fluid over a Linearly Stretching Sheet," Commun. Nonlinear Sci. Numer. Simul., 17, 699-707.

https://dx.doi.org/10.1016/j.cnsns.2011.05.042
Ibrahim, W. and Makinde, O. D., 2016, "Magnetohydrodynamic Stagnation Point Flow and Heat Transfer of Casson Nanofluid Past a Stretching Sheet with Slip and Convective Boundary Condition," Journal of Aerospace Engineering, 29(2), Article \# 04015037. http://dx.doi.org/10.1061/(ASCE)AS.1943-5525.0000529

Ibrahim, W. and Makinde, O. D., 2016, "Magnetohydrodynamic Stagnation Point Flow of a Power-Law Nanofluid towards a Convectively Heated Stretching Sheet with Slip," Proceedings of the Institution of Mechanical Engineers, Part E: Journal of Process Mechanical Engineering, 230(5), 345-354.

https://dx.doi.org/10.1177/0954408914550357

Ishak, A., 2011, "MHD Boundary Layer Flow due to an Exponentially Stretching Sheet with Radiation Effect," Sains Malaysiana, 40, 391395.

Khan, W. A., Makinde, O. D. and Khan, Z. H., 2016, "Non-Aligned MHD Stagnation Point Flow of Variable Viscosity Nanofluids past a Stretching Sheet with Radiative Heat," International Journal of Heat and Mass Transfer, 96, 525-534.

http://dx.doi.org/10.1016/j.ijheatmasstransfer.2016.01.052

Kumaran, V. and Ramanaiah, G., 1996, "A Note on the Flow over a Stretching Sheet," Acta Mech., 116, 229-233.

https://doi.org/10.1007/BF01171433

Magyari, E. and Keller, B., 1999, "Heat and Mass Transfer in the Boundary Layers on an Exponentially Stretching Continuous Surface," J. Phys. D Appl. Phys., 32(5), 577-585. https://doi.org/10.1088/0022-3727/32/5/012

Mandal, I.C. and Mukhopadhyay, S., 2013, "Heat Transfer Analysis for Fluid Flow over an Exponentially Stretching Porous Sheet with Surface Heat Flux in Porous Medium," Ain Shams Engineering J., 4, 103-110. http://dx.doi.org/10.1016/j.asej.2012.06.004

Miklavcic, M. and Wang C.Y., 2006, "Viscous Flow due to a Shrinking Sheet," Q. J. Appl. Math., 64, 283-290. https://dx.doi.org/10.1090/S0033-569X-06-01002-5

Mukhopadhyay, S., 2013, "Slip Effects on MHD Boundary Layer Flow over an Exponentially Stretching Sheet with Suction/Blowing and Thermal Radiation," Ain Shams Engineering J., 4, 485-491. http://dx.doi.org/10.1016/j.asej.2012.10.007

Norhafizah, M.S., Salleh, M.Z. and Nazar, R., 2013, "Numerical Solution of Flow and Heat Transfer over a Stretching Sheet with Newtonian Heating using the Keller Box Method," Procedia Engineering, 53, 542-554.

http://dx.doi.org/10.1016/i.proeng.2013.02.070

Pal, D. and Hiremath, P.S., 2010, "Computational Modeling of Heat Transfer over an Unsteady Stretching Surface Embedded in a Porous Medium," Meccanica, 45, 415-424.

https://dx.doi.org/10.1007/s11012-009-9254-7

Salleh, M.Z. Nazar, R. and Pop, I., 2010, "Boundary Layer Flow and Heat Transfer over a Stretching Sheet with Newtonian Heating," J. of the Taiwan Institute of Chemical Engineers, 41(6), 651-655. http://dx.doi.org/10.1016/j.jtice.2010.01.013

Schlichting, H. and Gersten, K., 2003, Boundary Layer Theory, Springer-Verlag Berlin Heidelberg, New York.

Sharma, P.R. and Singh, G., 2010, "Steady MHD Natural Convection Flow with Variable Electrical Conductivity and Heat Generation along 
an Isothermal Vertical Plate," Tamkang J. Science and Engineering, 13, 235-242.

Singh, G. and Makinde, O. D., 2015, "Mixed Convection Slip Flow with Temperature Jump along a Moving Plate in Presence of Free Stream," Thermal Science, 19(1), 119-128.

https://dx.doi.org/10.2298/TSCI120718110S
Soid, S.K., Kechil, S.A., Shah, A.H.M., Ismail, N.Z. and Halim, S.N.S.A., 2012, "Hydromagnetic Boundary Layer Flow over Stretching Surface with Thermal Radiation," World Applied Sciences J., 17, 33-38.

Yao, S., Fang, T. and Zhong, Y., 2011, "Heat Transfer on a Generalized Stretching/Shrinking Wall Problem with Convective Boundary Condition," Commun. Nonlinear Sci. Numer. Simul., 16, 752-760. http://dx.doi.org/10.1016/j.cnsns.2010.05.028 